\title{
PERANCANGAN ALAT UKUR KADAR ALKOHOL MENGGUNAKAN SENSOR MQ-3 BERBASIS MIKROKONTROLER ATMEGA16
}

\author{
I Gede Surya Merta ${ }^{1}$, I Gusti Agung Widagda ${ }^{1}$, Ida Bagus Alit Paramarta ${ }^{1}$
}

\author{
${ }^{1}$ Jurusan Fisika, Fakultas Matematika dan Ilmu Pengetahuan Alam, \\ Universitas Udayana, Kampus Bukit Jimbaran, Badung, Bali Indonesia 80361. \\ "Email : igedesuryamerta@gmail.com
}

\begin{abstract}
ABSTRAK
Telah berhasil dirancang alat ukur kadar alkohol menggunakan sensor MQ-3. Kadar alkohol yang terdeteksi diolah untuk ditampilkan pada GUI Visual Basic 6.0 melalui beberapa rangkaian yaitu rangkaian sensor, rangkaian minimum sistem ATmega16, rangkaian regulator tegangan 5V, modul komunikasi serial $\mathrm{CH} 340$ dan GUI Visual Basic 6.0. Seluruh rangkaian diaktifkan oleh rangkaian regulator 5VDC. Rentang pengukuran alat ini mengukur kadar alkohol pada rentang $0 \%$ sampai $70 \%$, kadar yang terukur oleh alat akan digolongkan sesuai dengan peraturan Pemerintah Republik Indonesia. Cara kerja alat ini memanfaatkan karakteristik sensor MQ-3 yang memiliki perubahan tegangan keluaran berupa sinyal analog, dimana tegangan keluaran sebanding dengan perubahan kadar gas alkohol yang dideteksi. Rangkaian ATmega16 adalah pusat dari semua pemrosesan data, proses konversi data analog sensor menjadi data digital yang diubah menjadi kadar alkohol oleh mikrokontroler. Data kadar alkohol yang telah diolah akan ditampilkan pada GUI Visual Basic 6.0 melalui komunikasi serial oleh modul CH340. Kesesuaian alat rancangan dengan kadar alkohol sampel yang diperoleh dari hasil analisa regresi linier data pengujian alat rancangan yaitu sebesar $99,57 \%$.
\end{abstract}

Kata kunci: alat ukur kadar alkohol, sensor MQ-3, modul CH340, mikrokontroler, GUI Visual Basic 6.0.

\begin{abstract}
It has been successfully designed an alcohol levels measuring instrument using MQ-3 sensor. The detected alcohol levels processed to be displayed on GUI Visual Basic 6.0 through several circuits, the sensor circuit, the Atmegal6 microcontroller minimum system, $5 \mathrm{~V}$ voltage regulator circuits, CH340 serial communication module and GUI Visual Basic 6.0. The entire circuit is powered by $5 \mathrm{VDC}$ regulator circuit. The measurement range of this instrument measures alcohol level in the range 0\% to 70\%, the levels measured by the instrument will be classified according to the regulations sets by Indonesian government. The instrument works by employing the characteristics of the MQ-3 sensor which has proportional voltage change with alcohol levels that is detected. The Atmegal6 circuit is the main unit for data processing, the microcontroller performs the analog to digital data conversion and estimates this digital data into matching alcohol levels. Alcohol content data that processed is displayed on the GUI Visual Basic 6.0 through serial communication module CH340. Detected alcohol levels by this instrument compared with the alcohol levels of sample is match by $99.57 \%$.
\end{abstract}

Keywords: alcohol measuring instrument, sensor MQ-3, CH340 module, microcontroller, GUI Visual Basic 6.0. 


\section{PENDAHULUAN}

Alkohol adalah suatu zat yang banyak dimanfaatkan pada kehidupan sehari-hari, alkohol banyak dijumpai pada minuman. Alkohol juga dapat terkandung dalam obat-obatan, parfum, larutan atau bahan keperluan laboratorium, industri kimia dan lain-lain. Alkohol yang terkandung dalam minuman biasanya dijumpai dalam beberapa merek minuman yang tergolong minuman keras biasanya dinyatakan dalam persentase $(\%)$.

Pengukuran kadar alkohol masih banyak dilakukan secara manual yaitu dengan memakai hitungan takaran disertai perhitungan-perhitungan kimia tertentu, metode seperti ini kurang akurat dan efisien (Syahrul, 2013). Metode atau alat yang biasanya digunakan salah satunya metode analisis, digunakan alat Gas Chromatography (GC), pengukuran alkohol dengan berat jenis piknometer dan metode hidrometer alkohol (Vikri Satria, 2013). Alat ukur kadar alkohol keberadaannya sangat langka dan terbatas. Keberadaannya hanya dijumpai di industri besar dan laboratorium penelitian. Disamping keberadaan yang terbatas, alat ukur ini harganya juga relatif mahal.

Berdasarkan kelemahan atau kekurangan dari alat ukur kadar alkohol tersebut maka perlu dirancang alat ukur yang lebih efisien dan cepat dalam pengukuran yaitu dengan menggunakan sensor MQ-3 berbasis mikrokontroler ATmega16. Sensor gas MQ-3 merupakan sensor gas yang memiliki sensitifitas tinggi dan respon cepat dalam mendeteksi alkohol, memiliki ketahanan baik terhadap asap dan uap.

\section{TINJAUAN PUSTAKA}

\subsection{Sensor MQ-3}

Sensor adalah suatu alat yang mampu mendeteksi fenomena fisika atau kimia. Sensor MQ3 memiliki nilai resistansi Rs, yang nilainya dapat berubah bila mendeteksi gas metana dan alkohol di udara. Rangkaian minimum sensor MQ-3 ini sangat sederhana seperti tampak pada Gambar 2.1. Rangkaian terdiri dari 1 buah variabel resistor dan pin $\mathrm{H}$ yang dihubungkan dengan tegangan sebesar 5 V.

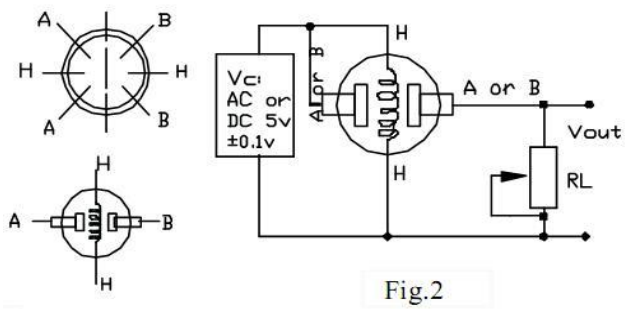

Gambar 2.1. Sensor MQ-3 (Galuh, 2013)

\subsection{Mikrokontroler ATmega16}

Mikrokontroler ATmega16 merupakan mikrokontroler 8 bit yang dikeluarkan oleh Atmel pada tahun 1996. Mikrokontroler ATmega16 ini dilengkapi fitur-fitur seperti ADC internal, EEPROM Internal, Timer/Counter serta eksekusi program yang lebih cepat karena sebagian intruksi dieksekusi dalam satu siklus. Sehingga dengan fiturfitur yang lengkap ini akan mempermudah dalam aplikasi perancangan sistem elektronika seperti robot, perlatan telekomunikasi dan otomatis industri. Konfigurasi pin ATmega16 dapat dilihat pada Gambar 2.2.

\begin{tabular}{|c|c|c|c|c|c|}
\hline (XCK/TO) & PBO & 1 & 40 & 巳 PAO & $(A D C 0)$ \\
\hline (T1) & PB1 & 2 & 39 & 巨 PA1 & (ADC1) \\
\hline (INT2/AINO) & PB2 & 3 & 38 & 曰 PA2 & (ADC2) \\
\hline (OCO/AIN1) & PB3 & 4 & 37 & 巨 $\mathrm{PA3}$ & (ADC3) \\
\hline 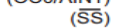 & PB4 & 5 & 36 & PA4 & (ADC4) \\
\hline (MOSI) & PB5 & 6 & 35 & 口 PA5 & (ADC5) \\
\hline (MISO) & PB6 & 7 & 34 & PA6 & (ADC6) \\
\hline (SCK) & PB7 & 8 & 33 & 巨 PA7 & (ADC7) \\
\hline & ESET & 9 & 32 & 巨 ARE & \\
\hline & vcc & 10 & 31 & GND & \\
\hline & GND & 11 & 30 & 巨 $\mathrm{AVC}$ & \\
\hline & TAL2 L & 12 & 29 & P PC7 & (TOSC2) \\
\hline & TAL1 & 13 & 28 & 口 PC6 & (TOSC1) \\
\hline$(R \times D)$ & PDO & 14 & 27 & P PC5 & (TDI) \\
\hline$(\mathrm{T} \times \mathrm{D})$ & PD1 & 15 & 26 & PC4 & (TDO) \\
\hline (INTO) & PD2 & 16 & 25 & 巨 $\mathrm{PC} 3$ & (TMS) \\
\hline (INT1) & PD3 & 17 & 24 & PC2 & (TCK) \\
\hline (OC1B) & PD4 & 18 & 23 & 马 $\mathrm{PC} 1$ & (SDA) \\
\hline (OC1A) & PD5 & 19 & 22 & 巨 PCO & (SCL) \\
\hline (ICP1) & PD6 ᄃ & 20 & 21 & PD7 & (OC2) \\
\hline
\end{tabular}

Gambar 2.2 Konfigurasi pin ATmega16 (Anonim, 2016).

\subsection{Komunikasi Serial}

Komunikasi serial merupakan pengiriman data satu persatu secara berurutan. Komunikasi data serial ada dua yaitu synchronous dan asynchronous. Komunikasi serial sychronous mengirimkan data beberapa byte atau karakter yang masih memerlukan konfirmasi setiap pengiriman data. Sedangkan dalam komunikasi serial Asynchronous setiap pengiriman data satu byte, tidak diperlukan konfirmasi penerimaan data. Pada mode Asynchronous, karakter data yang dikirim berada 
diantara bit start yang bernilai 0 (low) dan bit stop selalu 1 (high) (Suyadi, 2012).

\subsection{Visual Basic 6.0}

Visual BASIC (Beginners All-Purpose Symbolic Instruction Code) merupakan sebuah pemrograman yang digunakan untuk membuat suatu aplikasi atau graphical user interface (GUI) program pada operating system Microsoft Windows. Dengan fasilitas data access maka developer bisa dengan mudah menghubungkan aplikasi desktopnya, tidak hanya ke personal database seperti MS Access 2000, namun juga ke MS SQL Server (Pangestu, 2013).

\subsection{Modul CH340 (USB to TTL)}

IC CH340 merupakan suatu IC yang digunakan untuk mengkonversi USB ke interface serial, USB ke IrDA (Infrared Data Association) inframerah atau USB ke interface printer.

\subsection{Alkohol}

Alkohol adalah senyawa seperti air yang neniliki gugus fungsional - $\mathrm{OH}$ yang terikat pada rantai karbon alifatik. Salah satu sifat alkohol, memiliki titik didih yang tinggi dibandingkan alkana-alkana yang jumlah atom $\mathrm{C}$ nya sama. Menurut keputusan presiden Republik Indonesia Nomer 74 tahun 2013 mengatur pengawasan dan pengendalian minuman beralkohol. Minuman beralkohol golongan A (1\% sampai 5\%), golongan B (6\% sampai 20\%) dan golongan C (21\% sampai 55\%) (Kemendag, 2015).

\section{METODE PENELITIAN}

\subsection{Alat dan Bahan penelitian}

Alat-alat yang digunakan dalam penelitian ini yaitu komputer, downloader ATmega16, multimeter, pinset, solder, obeng, tang, gunting, bor, timbangan, pipet. Serta bahan-bahan yang digunakan sensor MQ-3, mikrokontroler ATmega16, kapasitor, resistor, kabel penghubung, project board, kristal osilator $12 \mathrm{Mhz}$, diode bridge, IC regulator 7805 , pin male header, pin female header, push button, led, PCB, timah, spacer, heatsink dan alkohol.

\subsection{Diagram Blok Alat}

Diagram blok rangkaian pendeteksi kadar alkohol berbasis ATmega16 dengan interface database Visual Basic 6.0, diperlihatkan pada Gambar 3.1

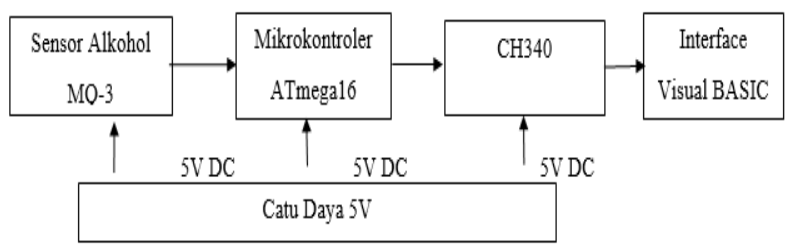

Gambar 3.1 Diagram blok rancangan pengukur kadar alkohol menggunakan sensor MQ-3

\subsection{Kalibrasi Alat}

Proses kalibrasi dilakukan di Lab Analitik Universitas Udayana menggunakan alat Gas Chromatography sebagai pembuatan sampel teruji. Sampel yang telah dibuat akan menjadi acuan dalam proses kalibrasi alat rancangan.

\subsection{Perancangan Perangkat Lunak}

Perancangan perangkat lunak (software) merupakan proses perancangan pembuatan program yang akan dijalankan oleh mikrokontroler. Diagram alir perangkat lunak alat ukur kadar alkohol seperti tampak pada Gambar 3.2. 


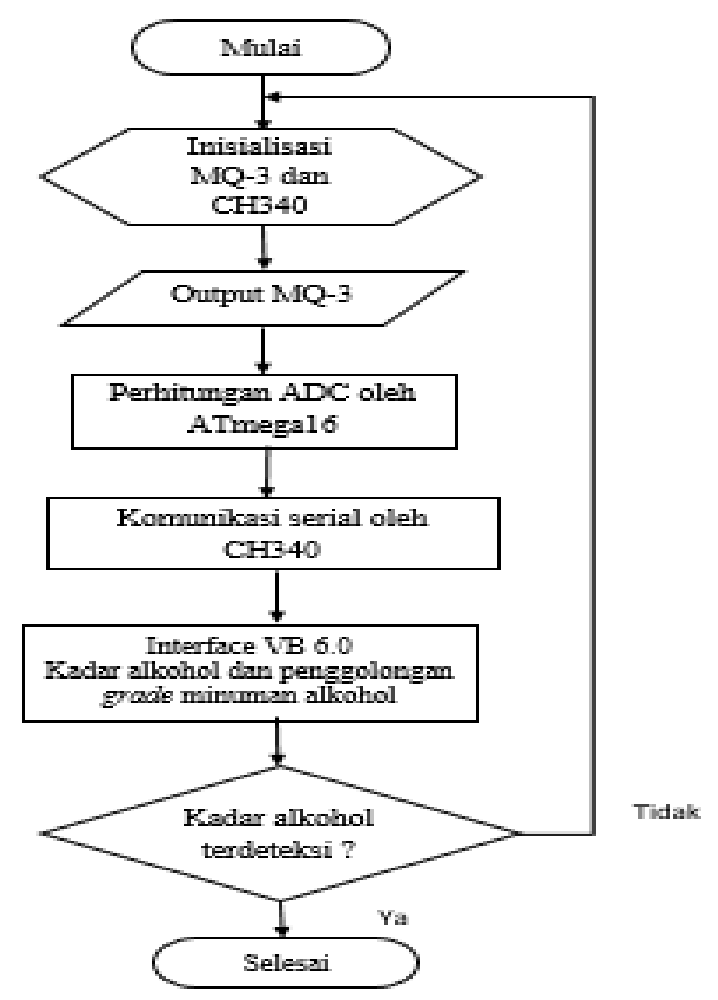

Gambar 3.2 Diagram alir alat pengukuran kadar alkohol.

\section{HASIL DAN PEMBAHASAN}

\subsection{Hasil}

Hasil yang didapatkan dari penelitian ini adalah alat ukur kadar alkohol menggunakan sensor MQ-3 berbasis mikrokontroler ATmega16. Alat ukur ini terdiri dari dua bagian yaitu perangkat keras (hardware) dan perangkat lunak (software). Perangkat keras terdiri dari sensor MQ-3, rangkaian daya 5 volt, rangkaian sistem minimum ATmega16 dan modul $\mathrm{CH} 340$. Berikut tampilan perangkat keras dan interface alat pengukur kadar alkohol yang ditunjukan pada Gambar 4.1.

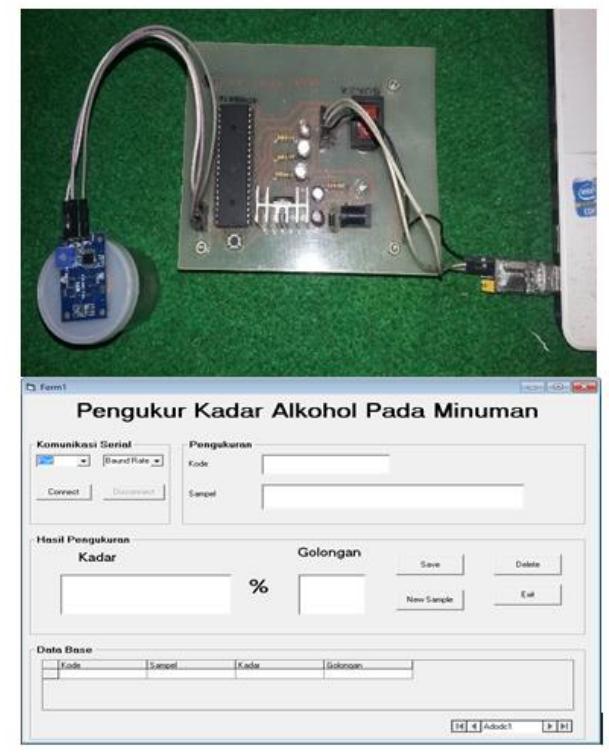

Gambar 4.1 Alat ukur kadar alkohol menggunakan sensor MQ-3 berbasis mikrokontroler ATmega16 dan tampilan GUI alat ukur alkohol.

\subsection{Pembahasan Hardware dan Software}

Alur respon sinyal dimulai dari rangkaian sensor MQ-3 mendeteksi kadar alkohol menjadi tegangan keluaran sensor. Tegangan keluaran yang terdeteksi akan menghasilkan perubahan sebanding dengan perubahan kadar alkohol yang dideteksinya. Tegangan yang dihasilkan dari sensor MQ-3 ini akan diteruskan ke mikrokontroler ATmega16 pada pin A.0 yang adalah pin input/output dua arah dan masukan ADC yang mengkonversi sinyal analog sensor MQ-3 yang berupa tegangan menjadi data digital. Pengkonversian dan pengolahan data yang diterima mikrokontroler diatur oleh program yang didownload pada mikrokontroler ATmega16. Setelah data digital MQ-3 dikonversi menjadi data digital, kemudian sinyal digital dikirimkan melalui komunikasi serial $\mathrm{CH} 340$ yang dipasang pada port USB laptop, dimana $\mathrm{CH} 340$ ini yang bertugas mengirimkan data digital yang akan ditampilkan pada GUI visual basic 6.0. Setelah data yang diterima oleh komputer ditampilkan pada visual basic dengan mengatur baud rate sebesar 9600 pada GUI Visual Basic dimana penentuan baud rate yang digunakan dicocokan dengan kristal external yang terpasang pada minimum sistem mikrokontroler ATmega16 yaitu menggunakan kristal sebesar 12 Mhz. Setelah komunikasi mikrokontroler 
ATmega16 dan komputer terhubung dengan benar, data digital yang diolah akan ditampilkan pada GUI Visual Basic 6.0 berupa persentase kadar alkohol beserta golongannya sesuai dengan peraturan

\subsection{Kalibrasi}

Kalibrasi sensor gas MQ-3 dilakukan di Lab Analitik Universitas Udayana. Pembuatan sampel alkohol menggunakan teknik pengenceran dan diuji dengan alat Gas Chromatography dan didapatkan konsentrasi alkohol sebesar $86 \%$ selanjutnya diencerkan menjadi 8 jenis sampel sebesar 5\%, $10 \%, 20 \%, 30 \%, 40 \%, 50 \%, 60 \%$ dan $70 \%$. Proses kalibrasi dilakukan dengan pembacaan nilai ADC yang dihasilkan sensor terhadap sampel alkohol teruji, pada kalibrasi ini menggunakan sebanyak 8 buah sampel (Mustafa, 2014). Pada proses kalibrasi kondisi sampel pengujian diperlakukan sama yaitu berat sampel sebesar 1 gram dan jarak antara sensor dan alkohol yaitu $2 \mathrm{~cm}$. Serta waktu pengukuran dibatasi maksimal selama 30 detik. Adapun data kalibrasi sensor MQ-3 terhadap sampel yang teruji ditampilkan pada Tabel 4.1.

Berdasarkan data kalibrasi sensor MQ-3 yang ditunjukan pada persamaan garis polinomial pada Gambar 4.2. Selanjutnya akan dilakukan penyesuaian pada program yang didownload ke mikrokontroler ATmega16. Penyesuaian program dilakukan dengan memasukan persamaan garis pada subprogram kalibrasi ke mikrokontroler.

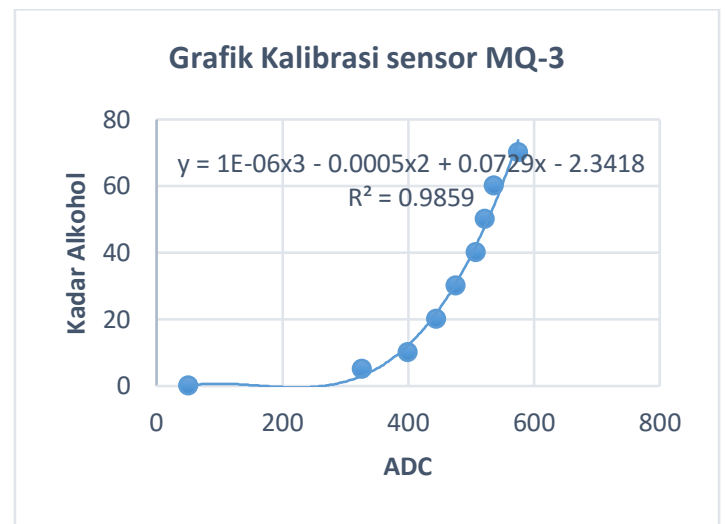

Gambar 4.2 Grafik kalibrasi sensor MQ-3 pemerintah. Kadar alkohol yang terukur dapat disimpan pada database yang terkoneksi dengan Visual Basic 6.0.

\subsection{Pengujian Alat Rancangan}

Pengujian rancangan alat ukur kadar alkohol dengan menggunakan sensor MQ-3 berbasis ATmega16 dilakukan dengan cara membandingkan hasil pengukurannya dengan kadar minuman beralkohol berijin yang beredar pada masyarakat yang tertera pada label kadar alkohol dari instansi pemerintahan BPOM. Hasil pengujian alat ditunjukan oleh Tabel 4.2.

Dari data yang diperoleh pada Tabel 4.2 selanjutnya diplot sebagai grafik kesesuaian ratarata hasil pengukuran antara alat rancangan dengan alat pembanding (label pada minuman), seperti yang ditunjukan pada Gambar 4.3

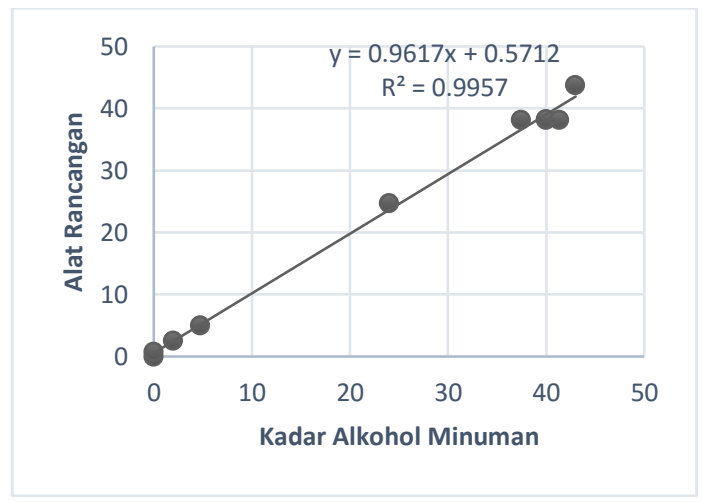

Gambar 4.3 Grafik kelinieran hasil pengujian alat

Gambar 4.3 menunjukan koefisien determinasi $\left(R^{2}\right)$ yang diperoleh dari hasil analisa data pengujian alat rancangan yaitu sebesar 0,9957. Koefisien tersebut menyatakan bahwa kesesuaian alat rancangan dengan label kadar alkohol adalah sebesar $99,57 \%$. 
Perancangan Alat Ukur Kadar Alkohol Menggunakan Sensor MQ-3 Berbasis..........

(I Gede Surya Merta dkk.)

Tabel 4.1 Data kalibrasi sensor MQ-3 terhadap sampel teruji

\begin{tabular}{|c|c|c|c|c|c|c|}
\hline No & $\begin{array}{c}\text { Kadar } \\
\text { Alkohol }(\%)\end{array}$ & $\begin{array}{l}\text { Tegangan } \\
\text { (V) }\end{array}$ & $\begin{array}{l}\text { Nilai } \\
\text { ADC }\end{array}$ & $\begin{array}{l}\text { Jarak sensor dengan } \\
\text { sampel }(\mathrm{cm})\end{array}$ & $\begin{array}{c}\text { Waktu } \\
\text { Pengukuran (s) }\end{array}$ & $\begin{array}{c}\text { Berat Sampel Uji } \\
(\mathrm{g})\end{array}$ \\
\hline 1 & 0 & 0,24 & 50 & 2 & 30 & 1 \\
\hline 2 & 5 & 1,59 & 326 & 2 & 30 & 1 \\
\hline 3 & 10 & 1,95 & 399 & 2 & 30 & 1 \\
\hline 4 & 20 & 2,17 & 445 & 2 & 30 & 1 \\
\hline 5 & 30 & 2,32 & 475 & 2 & 30 & 1 \\
\hline 6 & 40 & 2,47 & 507 & 2 & 30 & 1 \\
\hline 7 & 50 & 2,55 & 522 & 2 & 30 & 1 \\
\hline 8 & 60 & 2,61 & 536 & 2 & 30 & 1 \\
\hline 9 & 70 & 2.81 & 575 & 2 & 30 & 1 \\
\hline
\end{tabular}

Tabel 4.2 Data hasil uji alat ukur kadar alkohol pada minuma

\begin{tabular}{|l|l|c|c|}
\hline No & $\begin{array}{c}\text { Merk } \\
\text { Minuman }\end{array}$ & $\begin{array}{c}\text { Kadar Alkohol } \\
\text { Pada Label (\%) }\end{array}$ & $\begin{array}{c}\text { Kadar Alkohol Pada } \\
\text { Alat Rancangan (\%) }\end{array}$ \\
\hline 1 & Sampel A & 0 & $(0 \pm 0)$ \\
\hline 2 & Sampel B & 0 & $(0,76 \pm 0,00)$ \\
\hline 3 & Sampel C & 2 & $(2,56 \pm 0,17)$ \\
\hline 4 & Sampel D & 4,75 & $(4,97 \pm 0,07)$ \\
\hline 5 & Sampel E & 24 & $(24,74 \pm 0,17)$ \\
\hline 6 & Sampel F & 37,5 & $(38,11 \pm 0,14)$ \\
\hline 7 & Sampel G & 40 & $(38,18 \pm 0,21)$ \\
\hline 8 & Sampel H & 40 & $(38,21 \pm 0,20)$ \\
\hline 9 & Sampel I & 41,40 & $(38,17 \pm 0,16)$ \\
\hline
\end{tabular}

\section{KESIMPULAN}

Dari hasil penelitian yang diperoleh dan pembahasan yang telah diuraikan telah berhasil dirancangan alat ukur kadar alkohol, maka dapat ditarik kesimpulan sensor MQ-3 memiliki karakteristik dimana sensor mempunyai sensitifitas tinggi terhadap gas alkohol serta tegangan keluaran sebanding dengan perubahan kadar gas alkohol yang dideteksi, menghabiskan daya sebesar $500 \mathrm{~mW}$ dan waktu pemanasan sensor selama 10 menit. Kesesuaian alat rancangan yang diperoleh dari hasil analisa regresi linier data pengujian alat rancangan yaitu sebesar 99,57\%.

\section{DAFTAR PUSTAKA}

Anonim, 2016. 8-bit AVR Microcontroler with $16 \mathrm{~K}$ Bytes In-System Programmable Flash. http://www.atmel.com/images/doc2466.pdf. [.Diakses pada tanggal 9 September 2016]
Kemendag. 2015. Peraturan Mentri Perdagangan Republik Indonesia.

Mustafa, Waslaluddin, A. Aminudin. 2014. Sistem Pendeteksi Kadar Alkohol Berbasis Mikrokontroler Pada Minuman Beralkohol Dengan Tampilan LCD. Bandung: Jurusan Pendidikan Fisika MIPA Universitas Pendidikan Indonesia.

Pangestu, Danu Wira. 2013. Modul Pelatihan Visual Basic-Access. Yogyakarta: Jurusan Teknik Elektro Universitas Negeri Yogyakarta.

Suyadi. 2012. Komunikasi Serial dan Port Serial (COM). Surakarta: Jurusan Teknik Informatika Universitas Muhammadiyah Surakarta.

Syahrul, Sri Nurhayati, Giri Rakasiwi. 2013. Pengatur Kadar Alkohol Dalam Larutan. Bandung: Jurusan Teknik Komputer Fakultas Teknik dan Ilmu Komputer Universitas Komputer Indonesia. 
Tuhu Prasetyo, Galuh. 2012. Simulator Pendeteksi Kadar Alkohol Pengemudi Berbasis Mikrokontroler ATmegal6. Skripsi. Jurusan Teknik Elektronika Fakultas Teknik Universitas Negeri Yogyakarta.
Vikri Satria, Ade. 2013. Rancangan Bangun Alat Ukur Kadar Alkohol Pada Cairan Menggunakan Sensor MQ-3 Berbasis Mikrokontroler AT89S51. Padang: Jurusan Fisika Universitas Andalas. 